\title{
ANÁLISE ESTRUTURAL E DEFORMACIONAL EM ZONAS DE CISALHAMENTO DE BAIXO MERGULHO E TRANSCORRENTES ASSOCIADAS A ZONA DE SUTURA DE ALTEROSA, NA REGIÃO DE CRISTINA E ITAJUBÁ -MG
}

\author{
IRAMAIA FURTADO BRAGA ${ }^{1}$ \& HANS DIRK EBERT ${ }^{2}(I N$ MEMORIAN)
}

\begin{abstract}
Resumo Na região de Cristina e Itajubá/MG, a sul do Cráton do São Francisco, afloram paragnaisses do Complexo Piracaia, granulitos e ortognaisses do Complexo Paraisópolis, que cavalgam os metassedimentos do Grupo Andrelândia e seu embasamento (Complexo Amparo/São Gonçalo do Sapucaí), metamorfisados em fácies anfibolito, e granitos associados intrudidos ou como lascas nas unidades. As estruturas dúcteis registram dois eventos tectônicos principais. Dn, de caráter tangencial, gerou a foliação regional Sn de direção NW-SE e baixo mergulho para SW com lineações de estiramento frontais, sendo relacionado à colisão do Bloco São Paulo (Terreno Socorro-Guaxupé) sobre a Placa São Francisco durante a Orogênese Brasília (630-610 Ma), cujo limite, a Zona de Sutura de Alterosa (ZSA), é marcado na área pela ZC de Lourenço Velho (ZCLV). As zonas de cisalhamento transcorrentes de Maria da Fé e Cristina, de direção NE-SW, sinistrais e de fácies granulito a anfibolito, promoveram uma deflexão progressiva da foliação $\mathrm{Sn}$ até a verticalização, sendo interpretadas como zonas de transferência. $\mathrm{Dn}+1$, de caráter transcorrente a transpressivo, formou a foliação milonítica $(\mathrm{Sn+1})$ ao longo de zonas transcorrentes também de direção NE-SW, mas dextrais e de fácies anfibolito baixo. Estas são relacionadas ao Cinturão Transpressivo Rio Paraíba do Sul, vinculado aos processos colisionais mais jovens da Faixa Ribeira (580-540 Ma). A análise de deformação pelos métodos de Fry e Rf/phi efetuda em gnaisses revelou predomínio de elipsóides de strain finito oblatos e da componente de cisalhamento puro sobre o simples na maioria das amostras. Cisalhamento simples predomina apenas em amostras próximas a ZCLV, onde ocorre grande número de indicadores cinemáticos de cavalgamento para NE, e que constitui importante zona de transporte de massas relacionado a ZSA. Constata-se uma obliqüidade entre o eixo maior da elipse de deformação, em relação à foliação, nos planos cinemáticos XZ e YZ, indicando deformação não coaxial nos dois planos. A análise por tipo de marcador indica que o quartzo exerceu fundamental importância reológica para o desenvolvimento de zonas de cisalhamento, acomodando com maior intensidade as tensões regionais, em relação ao feldspato, que não mostra variação substancial entre amostras pouco e muito deformadas.
\end{abstract}

Palavras-chaves: Placa São Francisco, Terreno Socorro-Guaxupé, Sutura de Alterosa, Cinturão Brasília x Cinturão Ribeira, tectônica colisional, transpressão, análise de deformação.

\begin{abstract}
STRUCTURAL AND STRAIN ANALYSIS IN LOW ANGLE AND TRANSCURRENT SHEAR ZONES AT CRISTINA AND ITAJUBA REGION-MG. The region of Cristina and Itajubá-MG, located south of São Francisco Craton, comprises paragneisses of the Piracaia Complex, granulites and ortogneisses of the Paraisópolis Complex which are overthrusted on metassediments of the Andrelândia Group and its basement (Amparo/São Gonçalo do Sapucai Complex), metamorphosed in the amphibolite facies. Ductile fabrics record two main tectonic events. A thrusting event (Dn) generated the regional Sn, which shows foliation with NW-SE strike and low dips to SW, in association with down dip stretching lineations. Dn is atributed to the collision of the São Paulo Block (Socorro-Guaxupé Terrane) to ENE onto the São Francisco Plate during the Brasilia Orogeny (630-610 Ma), whose limit, the Alterosa Suture Zone (ASZ), is marked in that area by the Lourenço Velho SZ. Sn also shows a progressive sinistral inflection to a almost vertical NE-SW orientaton along the Maria da Fé and Cristina strike slip shear zones. These amphibolite to granulite facies shear zones are consistent with the SW-NE compressive tectonic regime and are interpreted as lateral ramps of the Dn event. A Strike-slip/transpressive deformation $(\mathrm{Dn}+1)$ formed, in lower amphibolite facies, the mylonitic foliation $\mathrm{Sn}+1$, that occur along NE-SW trending dextral shear zones within the transpressive Rio Paraiba do Sul Belt, with is related to the younger Ribeira collision (590-560 Ma). The strain analysis using Fry and Rf/phi methods revealed oblate strain elipsoids, with predominance of pure shear component of over simple shear. Simple shear predominates only in samples close to the SLSZ, where kinematic markers indicate top movement to NE and constitutes an important zone of mass transport. The obliquity between the largest axis of the strain ellipse in relation to the foliation in planes XZ and YZ indicates non-coaxial deformation in both kinematic planes. The analyses of the strain ratio on these sections indicates that the quartz exerted strong rheologic importance for shear zone development, better accomodating the regional strains in relation to feldspars, that does not show substantial strain variation among samples with low and high deformation.
\end{abstract}

Keywords: São Francisco Plate, Socorro-Guaxupé Terrane, Alterosa Suture Zone, Brasília x Ribeira belts collision tectonics, transpression, strain analysis.

INTRODUÇÃO A região a sul do Cráton do São Francisco exibe uma compartimentação regional em blocos crustais, justapostos por processos colisionais através de zonas de cisalhamento de baixo ângulo de mergulho, as quais localmente evoluíram para sistemas transcorrentes. Seu substrato geológico foi construído através da colisão oblíqua de blocos crustais paleoproterozóicos contra as bordas sudoeste (Cinturão Orogênico Brasília ou Sistema Orogênico Tocantins Meridional) e sudes- te (Cinturão Orogênico Ribeira ou Sistema Orogênico Mantiqueira) do paleocontinente São Francisco durante a aglutinação de Gondwana Ocidental no Neoproterozóico (Ebert \& Hasui 1997, Campos Neto 2000, Trouw et al. 2000, Campos Neto et al. 2004, Heilbron et al. 2004). Rochas deste embasamento sofreram retrabalhamentos tectônicos e metamórficos, acreção crustal devido a subdução de litosfera oceânica e imbricação de sequências sedimentares e volcano-sedimentares derivadas da

1-Bolsista PRODOC/CAPES - Departamento de Geologia - Universidade Federal do Ceará (UFC), Campus do Pici, Blocos 912/913, 60.455-760, Fortaleza-CE. 085-30669873, fax 085-30669873, iramaiabraga@yahoo.com.br

2 - Departamento de Petrologia e Metalogenia (DPM)_Universidade Estadual Paulista (UNESP) - Rio Claro-SP. 
erosão do embasamento e de arcos magmáticos ao longo das margens ativas e bacias retro-arco. As zonas de sutura entre blocos crustais amalgamados, geralmente coincidentes com importantes zonas de cisalhamento regionais, tem sido identificadas através de contrastes litológicos, geocronológicos/isotópicos, no estilo metamórfico e das assinaturas gravimétricas e aeromagnetométricas.

A Zona de Sutura de Alterosa (ZSA), bem caracterizada por anomalias gravimétricas e magnetométricas (Haraly et al. 1985, Almeida \& Ebert 1998), marca o limite entre a Placa São Francisco, placa inferior, e o Bloco São Paulo (Terreno Guaxupé ou Nappe de Socorro-Guaxupé), entidade geotectônica de paleocontinente, que representa a placa superior.

A área estudada, região de Cristina e Itajubá, a sul de Minas Gerais (Fig. 1), é constituída por rochas do Complexo Amparo/ São Gonçalo do Sapucaí (granada-hornblenda biotita gnaisses e gnaisses migmatizados), Grupo Andrelândia (paragnaisses), Complexo Piracaia (biotita e/ou anfibólio gnaisses migmatizados), Complexo Paraisópolis (ortognaisses e gnaisses granulíticos) e rochas ígneas associadas (Morais et al. 1999).

Feições litoestruturais integradas a dados isotópicos $\mathrm{Sm} / \mathrm{Nd}$ e U/Pb (Braga 2002, Hackspacher et al. 2003) permitiram interpretar a zona de cisalhamento de baixo ângulo de Lourenço Velho (ZSLV), e sua continuação a ZC de Cristina, como um segmento deslocado da extremidade sudeste Zona de Sutura de Alterosa (ZSA), antes desta ser completamente destruída pelas estruturas superpostas do Cinturão Ribeira. Na área investigada esta zona de sutura é caracterizada pelo contato basal dos granulitos neoproterozóicos do Complexo Paraisópolis cavalgados sobre paragnaisses do Grupo Andrelândia e seu embasamento paleoproterozóico (Complexo Amparo/São Gonçalo do Sapucaí), ambos de fácies anfibolito. Estas feições atribuídas à colisão Brasília (ca. 630-610 ma) (Campos Neto et al 2004), apresentam-se segmentadas e rotacionadas pelo feixe NE-SW do Cinturão Transcorrente Rio Paraíba do Sul, vinculado aos processos colisionais do Cinturão Ribeira (580-540 ma).

Para avançar no entendimento das complexas relações entre as estruturas geradas por regimes compressional e transcorrente atribuídos, respectivamente, às orogêneses Brasilia e Ribeira, formadoras do arcabouço regional, este trabalho apresenta os resultados de uma análise estrutural geométrica e cinemática, desenvolvida da área de Cristina e Itajubá - Minas Gerais. Através da análise de deformação pretende-se contribuir também para uma melhor compreensão dos processos deformacionais que operam em crosta continental profunda, como a exposta na região, e trazer novos dados quantitativos, até então restritos ao Cinturão Ribeira adjacente (Dayan \& Keller, 1990; Campanha \& Sadowski, 2002).

\section{ARCABOUCCO ESTRUTURAL}

Elementos planares e lineares Os litotipos aflorantes na área exibem foliação gnáissica marcada pelo achatamento de agregados minerais quartzo-feldspáticos, bandamento composicional formado pela alternância de níveis centimétricos máficos e félsicos e foliação milonítica. A lineação de estiramento é definida pela orientação preferencial de cristais ou agregados de quartzo estirados/achatados e pelo alinhamento do eixo maior de porfiroclastos de feldspato. A orientação preferencial linear de plaquetas de biotita, de cristais de anfibólio ou de aglomerados de cristais caracteriza uma lineação mineral.

Em termos de atitudes, a foliação caracteriza-se por um comportamento geométrico complexo. Os estereogramas mostram isolinhas configurando guirlandas, indicando variação de mergulho e direção. Prevalecem as direções NE-SW, e mergulhos sub verticais ou com valores médios para SE (Fig. 2a). As lineações mostram caimento suave $\left(10^{\circ}\right)$ para SW ou NE (Fig. 2b).
A análise discriminatória da foliação em ângulo de mergulho, agrupados em intervalos de baixo $\left(0^{\circ}-30^{\circ}\right)$, médio $\left(31^{\circ}-60^{\circ}\right)$ e alto $\left(61^{\circ}-90^{\circ}\right)$ ângulos, evidenciou uma gradação de baixo mergulho preferencialmente para SW, passando a intermediário para S e alto para o quadrante SE (Figs. 3 a,c,e). A lineação de estiramento associada apresenta padrão mais constante, com caimento sub-horizontal para SW e, secundariamente, para NE (Fig.s 3 b,d,f).

$\mathrm{O}$ padrão geométrico e cinemático dessas estruturas e sua distribuição espacial indicam a existência de domínios parcialmente homogêneos. Estruturas de baixo mergulho (Sn) prevalecem na porção oeste da área (Fig. 4). São caracterizadas por foliação com mergulho médio inferior a $34^{\circ}$ para SW, lineação (Ln) frontal/oblíqua com caimento sub-horizontal para SW e se associam a paragêneses de fácies granulito a anfibolito. Feições cinemáticas são indicativas de movimentação de topo preferencialmente para NE, ocorrendo subordinadamente, movimentos normais para SW. Estruturas de baixo mergulho rotacionadas, constituem faixas próximas às zonas de cisalhamento transcorrentes de Maria da Fé e Cristina, nas quais a foliação Sn apresenta diferentes graus de inflexão sinistral e subverticalização, sem, no entanto, ter sofrido uma nova milonitização ou retrometamorfismo compatível com $\mathrm{Sn}+1$. Estruturas transcorrentes $\mathbf{S n + 1}$ ocorrem a leste da área, caracterizadas por foliação milonítica de direção NE-SW com mergulhos médios de $70^{\circ}$ para SE. Prevalecem lineações de estiramento $(\mathrm{Ln}+1)$ direcionais, com movimentação dominantemente dextral, e caimento inferior a $10^{\circ}$ para SW ou NE. Dobras abertas a apertadas com eixos em torno de NE-SW são freqüentes. As associações minerais relacionadas a tais estruturas são retrometamórficas, de fácies anfibolito baixo.

Zonas de cisalhamento Quatro zonas de cisalhamento de alto mergulho e uma de baixo mergulho recortam a área. A Zona de Cisalhamento de Lourenço Velho (ZCLV) constitui a principal superficie de baixo ângulo mergulho (Sn), e fica alojada no contato basal dos granulitos do Complexo Paraisópolis que cavalgam para NE os paragnaisses do Grupo Andrelândia e seu embasamento (Complexo Amparo/São Gonçalo do Sapucaí). Seu traçado, de direção aproximadamente E-W, sofre inflexão a norte de Itajubá, onde se conecta as zonas de cisalhamento transcorrentes sinistrais de Cristina e Maria da Fé, de fácies granulito a anfibolito. A Zona de Cisalhamento de Lourenço Velho constitui uma importante zona de transporte de massas com indicação de movimentação de topo para NE, sendo interpretada como um segmento Zona de Sutura de Alterosa, deslocado pelas zonas transcorrentes dextrais relacionadas ao Cinturão Transpressivo Rio Paraíba do Sul.

As zonas de Monte Sião (ZCMS) e de São Bento do Sapucaí (ZCSBS) constituem estruturas transcorrentes dextrais $(\mathrm{Sn}+1)$, de fácies anfibolito baixo, relacionadas ao Cinturão Transpressivo Rio Paraíba do Sul. A primeira, com traçado aproximadamente ENE, ao longo do qual são reconhecidas faixas milonitizadas de até cem metros de espessura, marca o contato entre biotita gnaisses migmatizados do Complexo Amparo com anfibólio biotita gnaisses do Grupo Andrelândia/São Gonçalo do Sapucaí. A Zona de Cisalhamento de Monte Sião marca o contato entre rochas do Complexo Paraisópolis com as do Grupo Andrelândia e do Complexo Piracaia. Seu traçado sinuoso orienta-se preferencialmente segundo direção a NE-SW e é caracterizado pela formação de foliação milonítica sub-vertical caindo para SE ou NW e lineação direcional sub-horizontal com caimento para NE ou SW. Em mapa a zona milonítica alcança até $1 \mathrm{~km}$ de largura.

As foliações de baixo mergulho (Sn) de direção NW-SE caracterizam rampa frontal ao longo da Zona de Cisalhamento de 


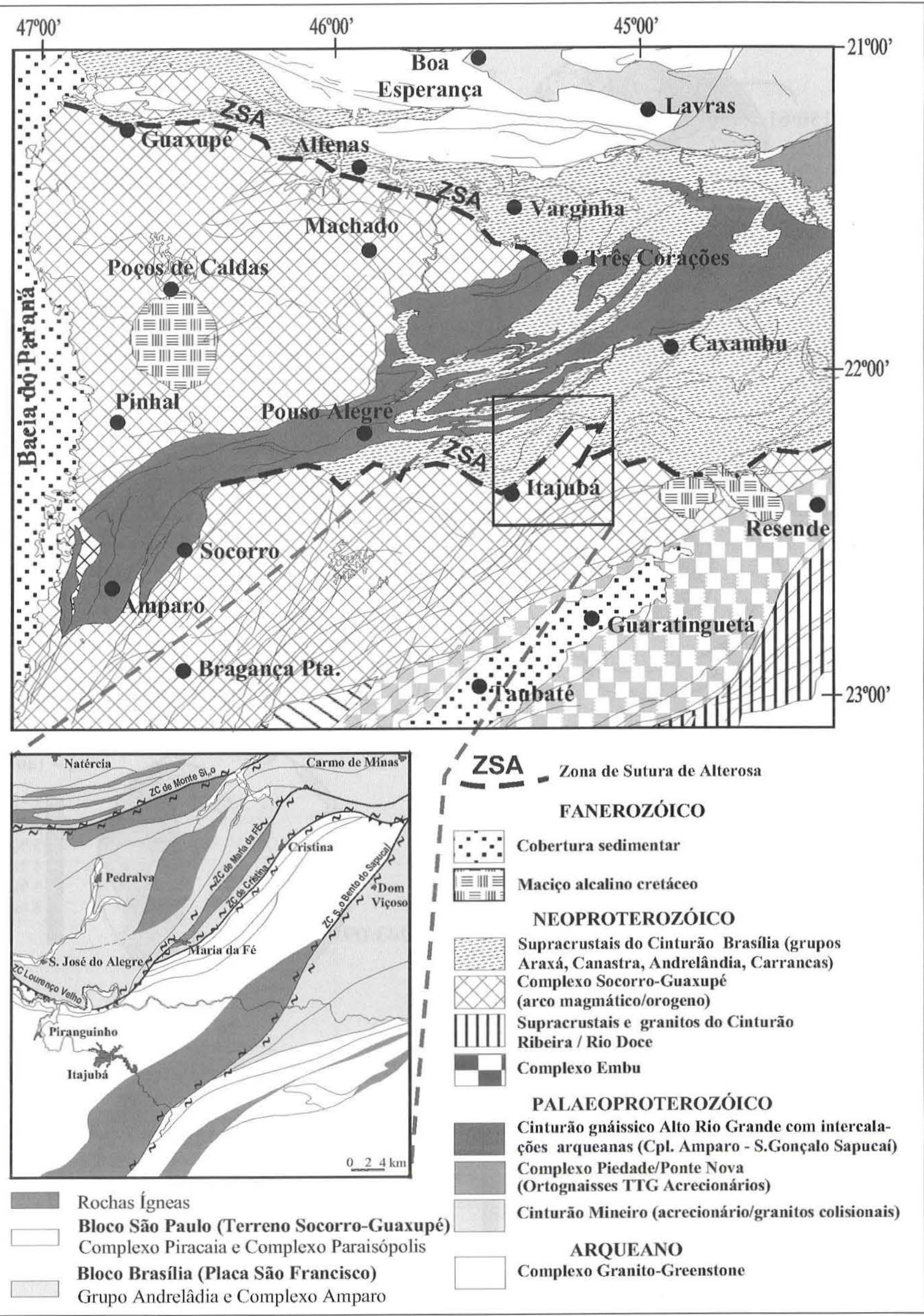

Figura 1-Mapa de associações litológicas do sul de Minas Gerais (simplificado de Morales, 1993) com a área estudada em destaque. 


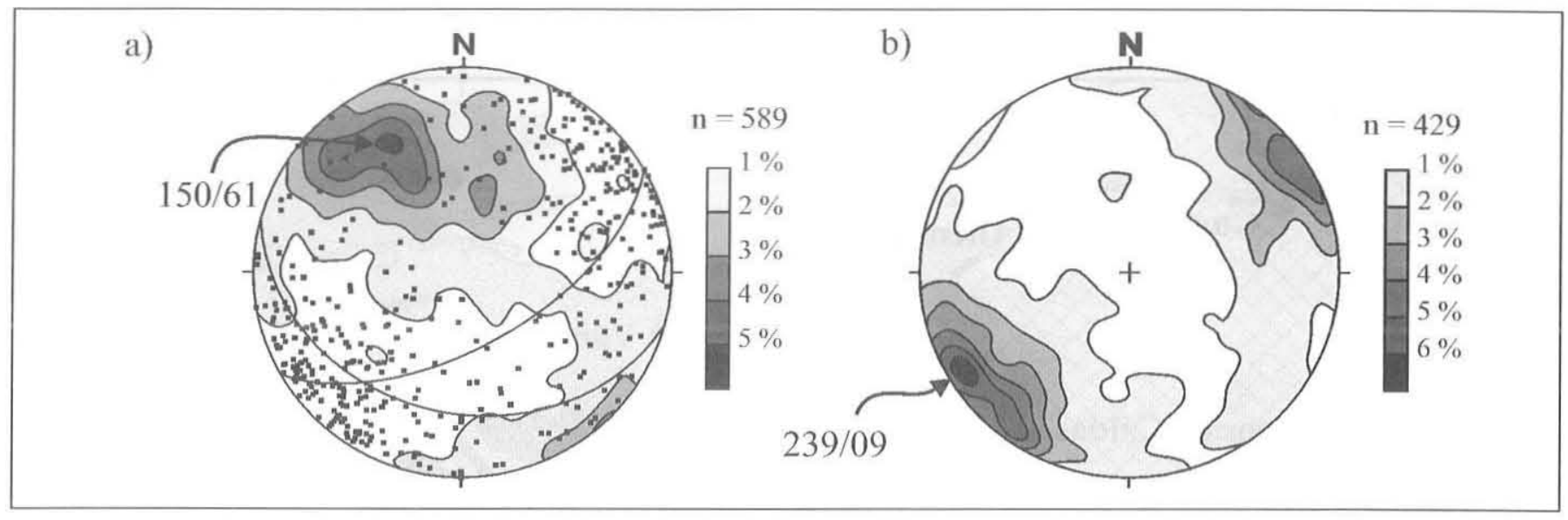

Figura 2 - Estereogramas de pólos de (a) foliação e (b) lineação. Pontos = lineação; $n=$ múmero de medidas.

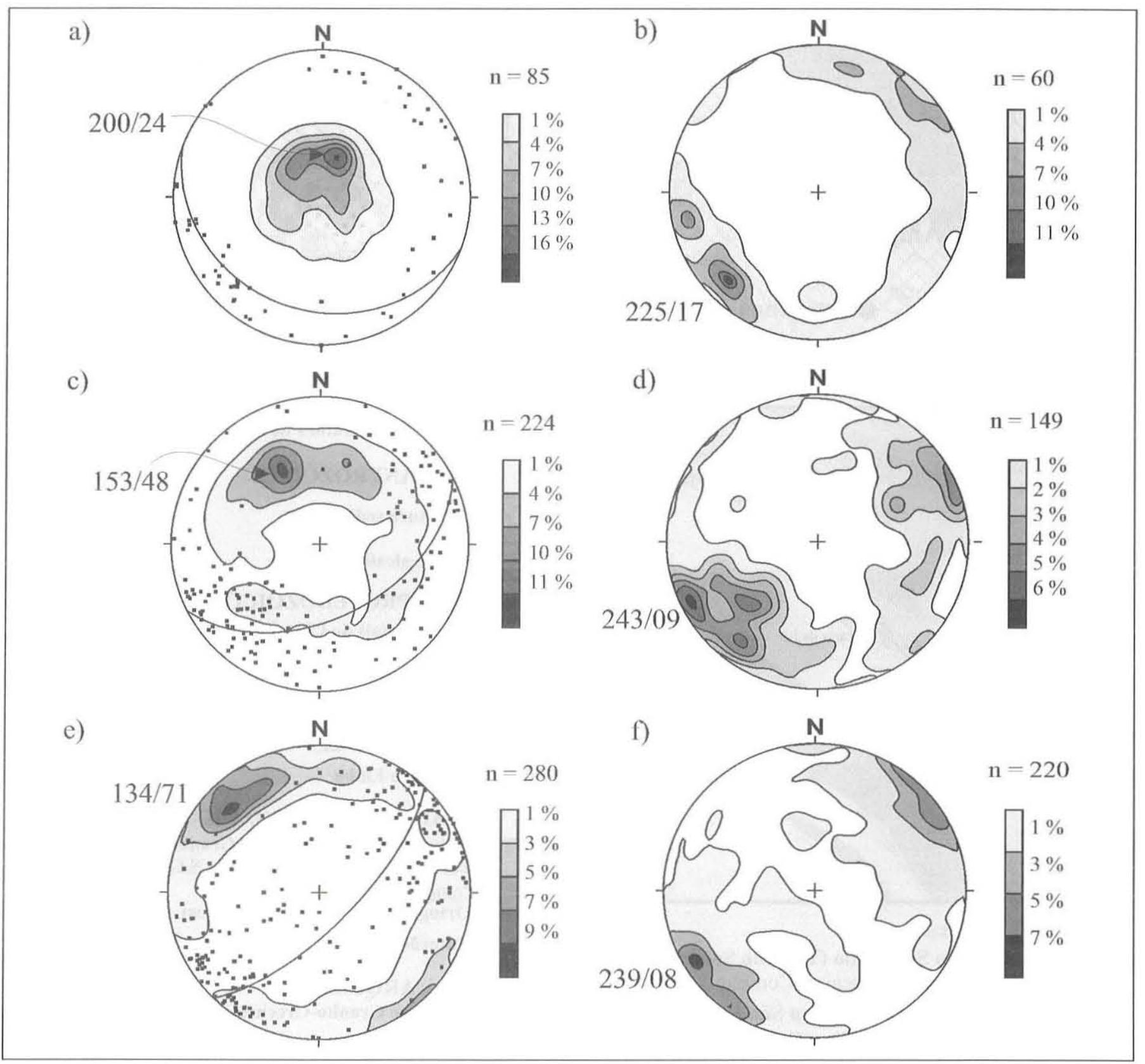

Figura 3 - Estereogramas para os intervalos de: (a) baixo $\left(0-30^{\circ}\right)$, (c) médio $\left(31-60^{\circ}\right)$, (e) alto (61-90\%) ângulos de mergulho de foliação. $(b, d, f)$ isolinhas de lineação associada aos respectivos intervalos. Pontos em $(a, c, e)=$ lineação; $n$ - número de medidas. 


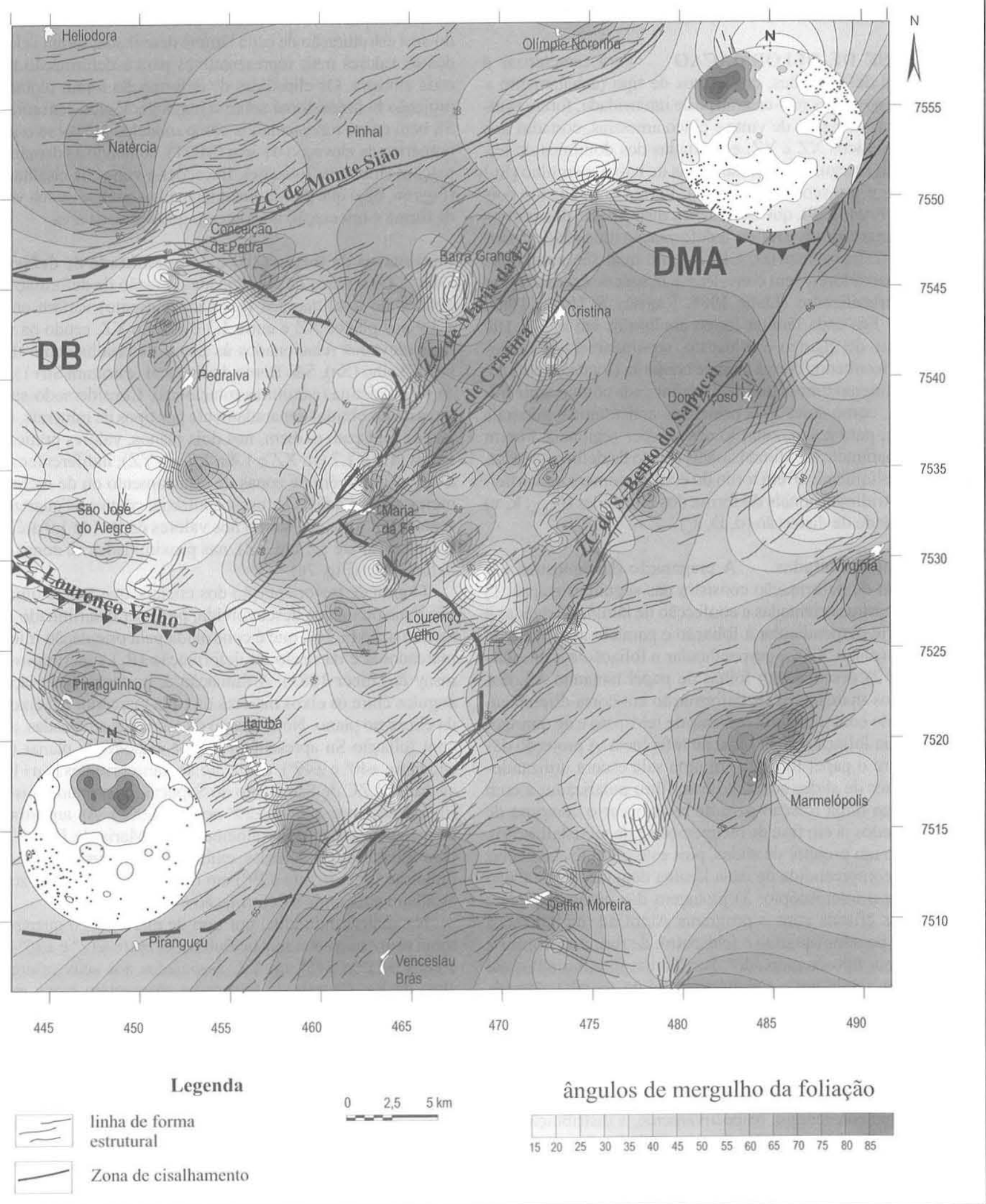

Figura 4-Curvas de iso-mergulhos da foliação e estereogramas dos dominios estruturais com predominio de baixo (DB) e médioalto (DMA) ângulos de mergulho. Nos estereogramas isolinhas=foliação; pontos=lineação.

Lourenço Velho, arranjo que provavelmente também ocorre a nordeste da localidade de Cristina. Estas feições são afetadas pelas transcorrências $\mathrm{Sn}+1$, que promovem deflexão progressiva de $\mathrm{Sn}$ até configurar estruturas verticais de direção NE-SW (Figs $3 \mathrm{a}-\mathrm{b}$ ), constituindo zonas de transferência, representadas na área, pelas zonas de cisalhamento transcorrentes sinistrais de Cristina e Maria da Fé, de fácies granulito a anfibolito. Esta rotação da foliação Sn, sem a modificação de atitudes da lineação associada, é interpretada como causada por zonas de transferência de movimentação sinistrais sobre feições de cavalgamento 
para NE, sendo cinematicamente compatíveis com o regime tectônico compressivo SW-NE e atribuídas ao evento (Dn).

ANALISE DE DEFORMAÇÃO Para caracterizar a natureza das deformações, em termos de tipo (achatamento $\mathrm{x}$ constricção, coaxial x não-coaxial) e de intensidade, foram estudadas lâminas delgadas de vinte e cinco amostras, cortadas nos planos cinemáticos XZ e YZ, e coletadas dos domínios de feições de baixo mergulho (Sn), estruturas de baixo mergulho (Sn) rotacionadas e transcorrentes $(\mathrm{Sn}+1)$. Foram empregados dois métodos: a) Fry (1979), que considera a distribuição dos centros dos cristais marcadores e reflete a deformação total (bulk strain) da amostra (cristais+matriz), e b) $R_{f / \phi}$, no qual são analisados apenas os marcadores, sem considerar a matriz de cristais muito finos ou recristalizados (Lislie 1985, Ramsay \& Huber 1983, Fiori 1997). Em cada lâmina foram analisados em média 100 (cem) cristais de quartzo e feldspato, separadamente, comparando-se os resultados com a análise conjunta (total de cristais). Este procedimento tornou possível avaliar cada componente mineral, isto é, como esses dois principais constituintes minerais contribuíram para a acomodação das tensões regionais. Foram calculados parâmetros bidimensionais (razão de deformação Rs, flutuação, obliqüidade $\theta$ ' em torno do eixo $\mathrm{X}$, número de vorticidade $\left.\mathrm{W}_{\mathrm{K}}\right)$ e tridimensionais de forma dos elipsóides $\left(\mathrm{K}_{\text {flimn }}, \mathrm{k}, \mathrm{v}\right)$ e de intensidade de distorção $\left(\mathrm{d}, \mathrm{D}, \varepsilon_{\mathrm{S}}\right)$.

Procedimentos adotados A preparação das amostras e a quantificação da deformação consistiu das seguintes etapas: 1) coleta de amostras orientadas e confecção de lâminas delgadas a partir de corte perpendicular à foliação e paralelo a lineação de estiramento (plano XZ), e perpendicular a foliação e a lineação (plano YZ); 2) desenho, em folhas de papel tamanho A3, dos contornos dos marcadores de deformação em cores diferenciadas, de acordo com o mineral (cristais de feldspato e de quartzo) e o traçado da foliação como linha de referência. A projeção das lâminas sobre o papel foi feita em uma sala escura utilizandose um projetor de slides adaptado com filtro polarizador e com placa de mica (cuja rotação permite reconhecer o contorno de cristais estirados já em fase de recuperação e de recristalização). Foi utilizado um projetor de slides, pois este permite considerar toda a área compreendida de cada lâmina delgada, o que é não possível sob o microscópio; 3) plotagem dos eixos maiores e menores dos cristais com o programa AutoCad, digitalizados em layers separados (quartzo e feldspato), de forma a permitir a análise $\mathrm{R}_{\mathrm{f} / \mathrm{\phi}}$ por tipo de marcador. Por lâmina foram obtidos até três arquivos, sendo um o somatório (total de cristais). Através de uma rotina em autolisp (ELIPSE.Isp) os layers com extensão DWG foram transformados em arquivos DAT, compostos pelas coordenadas X,Y da extremidade de cada eixo dos marcadores; 4) cálculo das razões de deformação $\left(R_{S X Z}\right.$ e $\left.R_{S Y Z}\right)$ utilizando-se o programa INSTRAIN 3.02 (Erslev 1993) pelos métodos de Fry e $\mathrm{R}_{\mathrm{f} / \phi}$, que consideram, respectivamente, a distribuição dos cristais e a forma dos grãos. Com o método de $\mathrm{R}_{\mathrm{t} / \mathrm{\phi}}$ foram obtidos os valores de $\mathrm{R}_{\mathrm{S}}$ do plano (média harmônica e aritmética), o valor de $\phi$ e o ângulo de flutuação $( \pm 2 \phi)$ para marcadores individuais e em conjunto. Pelo método de Fry obteve-se a elipticidade média do objeto (MOE), o ângulo ( $\theta^{\prime}$ ) entre o eixo maior da elipse de deformação e a linha de referência (foliação) e o erro médio para o total de cristais. Com o programa strain calculator (Holcombe 2000) e uma planilha Excel foram efetuados os cálculos dos valores de $\mathrm{R}_{\mathrm{SXY}}$, de X:Y:Z, dos parâmetros da forma dos elipsóides $(k, K, v)$ e de intensidade de deformação (d,D,,$\varepsilon)$, cujos resultados encontram-se reunidos na Tabela 1. Variações volumétricas de marcadores não foram consideradas.

A partir da comparação dos resultados da: a) razão de deformação dos marcadores nos dois planos, e b) variação angular do eixo maior dos marcadores em torno da foliação (isto é, o grau de anisotropia da rocha) obtidos pelos dois métodos e observando-se a estruturação de cada lâmina desenhada, foram selecionados os valores mais representativos para a deformação total de cada amostra. Os elipsóides de deformação foram plotados em projeção bidimensional sobre o mapa geológico-estrutural (Fig. 5), bem como representados como modelos 3D sobre o modelo numérico de elevação da área (MDT), contendo as demais informações (litotipos, foliações, lineações e zonas de cisalhamento) (Figs 6a, b), o que possibilita uma melhor análise da sua variação de forma e orientação no contexto geológico da área.

Parâmetros de forma (2D) e de intensidade de deformação (3D) Os valores da elipticidade ou razão de deformação (Rs) obtidos no total degrãos (quartzo+feldspato) variam entre 1.5 e 3.9 nos planos XZ e entre 1.3 e 3.7 em YZ, sendo os valores mais elevados relacionados às zonas de cisalhamento de Lourenço Velho (Sn), São Bento do Sapucaí (estrutura Sn+1), Maria da Fé e Cristina (estruturas rotacionas). Considerando-se os valores de Rs obtidos separadamente por tipos de minerais, os cristais de feldspato exibem, nos dois planos, valores praticamente iguais (1.5 a 1.7 em XZ e 1.4 a 1.7 em YZ), indiferentemente se a amostra provém de zonas de cisalhamento ou de rochas mais menos deformadas. De forma contrária, cristais de quartzo apresentam um forte acréscimo nos valores de Rs (de 1.9 até 5.9 em $\mathrm{XZ}$ e de 1.6 até $5.1 \mathrm{em} \mathrm{YZ),} \mathrm{nas} \mathrm{proximidades} \mathrm{de} \mathrm{zonas} \mathrm{de} \mathrm{alta}$ deformação (Fig. 7a).

O grau de iso-orientação dos cristais, que reflete uma foliação mais ou menos desenvolvida, pode ser determinado através da flutuação $( \pm 2 \phi)$, que é controlada pela orientação inicial dos marcadores e da razão de deformação $\left(R_{S}\right)$ superimposta (Ramsay \& Huber 1983). A flutuação é, portanto, a variação dos ângulos entre os eixos maiores da cada marcador e o eixo maior da elipse no plano. No conjunto de amostras analisadas, aquelas com foliação $\mathrm{Sn}$ apresentam menor anisotropia planar (flutuação entre $\left.\pm 40^{\circ} \mathrm{e} \pm 49^{\circ}\right)$, enquanto as transcorrentes $(\mathrm{Sn}+1)$, relacionadas à ZC de São Bento do Sapucaí, uma maior anisotropia (flutuação entre $\pm 23^{\circ}$ e $\pm 29^{\circ}$ no plano XZ). As amostras relacionadas às zonas de cisalhamento de Maria da Fé e Cristina, com foliações rotacionadas, exibem uma diminuição gradual da flutuação ( de $\pm 46^{\circ}$ até $\pm 29^{\circ}$ ) em direção ao centro das zonas de cisalhamento, onde a deformação é maior.

$\mathrm{Na}$ análise individual por tipo de marcador, o quartzo apresenta os menores valores de flutuação, entre $\pm 12^{\circ} \mathrm{e} \pm 35^{\circ} \mathrm{em} \mathrm{XZ}$ e entre $\pm 12^{\circ}$ e $\pm 45^{\circ}$ em YZ, associados aos seus valores mais altos de Rs. Cristais de feldspatos apresentam baixa razão de deformação, flutuação mais elevada (entre $\pm 30^{\circ} \mathrm{e} \pm 43^{\circ} \mathrm{em} \mathrm{XZ}$ e entre $\pm 40^{\circ} \mathrm{e} \pm 52^{\circ} \mathrm{em} \mathrm{YZ)}$.

Os valores de $\mathrm{K}_{\text {flimn }}<1$ e a plotagem dos dados no diagrama de Hsu indicam que a maioria das amostras analisadas, tanto em domínios de baixo mergulho como transcorrentes, corresponde a elipsóides de deformação finita oblatos (campo do achatamento), o que é compatível com razões de deformação semelhantes obtidas nos planos XY e XZ de cada amostra. O diagrama de Hsu (Hsu, 1966) também mostra que, para o total de grãos, o estiramento variou entre $18-60 \%$ ao longo do eixo X e de 0 a $30 \%$ em Y, com encurtamento entre $20-50 \%$ ao longo do eixo Z. A análise separada dos marcadores de feldspato revelou a seguinte deformação longitudinal média: estiramento de $20 \%$ ao longo do eixo $\mathrm{X}$ e de $15 \%$ em Y, com encurtamento de $22 \%$ em Z. O quartzo apresentou para a maioria das amostras estiramento de $40 \%$ em X e $25 \%$ em Y, com encurtamento de $25 \%$ em Z (Fig. 7 b).

A obliqüidade média expressa o ângulo $\left(\theta^{\prime}\right)$ do eixo maior das elipses em relação à foliação. Esse ângulo é igual a zero na deformação coaxial, enquanto valores mais elevados denotam a existência de componente rotacional (cisalhamento simples). Em 


\begin{tabular}{|c|c|c|c|c|c|c|c|c|c|c|c|c|c|c|c|c|c|}
\hline \multirow[b]{2}{*}{ amostra } & \multirow[b]{2}{*}{$\begin{array}{c}\text { Unidade } \\
\text { litológica }\end{array}$} & \multirow[b]{2}{*}{ rocha } & \multirow[b]{2}{*}{\begin{tabular}{|r|} 
localização \\
$\mathrm{X} / \mathrm{Y}$ (utm)
\end{tabular}} & \multirow[b]{2}{*}{\begin{tabular}{|l|} 
estrutura \\
\end{tabular}} & \multirow[b]{2}{*}{$\begin{array}{l}\text { atitude } \\
\text { foliação } \\
\text { lineação } \\
\end{array}$} & \multicolumn{4}{|c|}{ Parâmetros 2D } & \multicolumn{8}{|c|}{ Paramêtros 3D } \\
\hline & & & & & & $\operatorname{Rs}_{\mathrm{xz}}$ & $R s_{y z}$ & $\underset{1}{R_{x} s_{x y}}$ & $X: Y: Z$ & $\mathbf{k}$ & $K_{\log }$ & $\begin{array}{c}v \\
\text { Lode }\end{array}$ & d & D & $\begin{array}{c}\varepsilon s \\
\text { Nadai }\end{array}$ & $\begin{array}{l}\theta^{\prime} \\
x z\end{array}$ & $\begin{array}{l}\theta^{\prime} \\
\mathrm{YZ}\end{array}$ \\
\hline $\mathrm{F} 82 \mathrm{btt}$ & $\begin{array}{c}\text { Grupo } \\
\text { Andrelândia }\end{array}$ & bt-gnaisse & $\begin{array}{c}462.45 \\
7534.09 \\
\end{array}$ & $\operatorname{SnR}$ & $\begin{array}{l}\text { S } 42 / 19 \\
\text { L 12/15 } \\
\end{array}$ & 1,95 & 1,43 & 1,36 & 1.39:1.02:0.71 & 0,85 & 1,20 & 0,07 & 0,6 & 0,47 & 0,47 & 3 & 10 \\
\hline F83tt & $\begin{array}{c}\text { Grupo } \\
\text { Andrelândia }\end{array}$ & $\begin{array}{c}\text { anf-gr-bt } \\
\text { gnaisse bandado }\end{array}$ & $\begin{array}{c}463.10 \\
7536.70\end{array}$ & $\mathrm{Sn+1}$ & $\begin{array}{l}\text { S } 121 / 68 \\
\text { L } 32 / 02\end{array}$ & 1,95 & 1,46 & 1,34 & $1.38: 1.03: 0.71$ & 0,73 & 1,40 & 0,13 & 0,6 & 0,48 & 0,47 & 1 & 4 \\
\hline R86tt & $\begin{array}{c}\text { Grupo } \\
\text { Andrelândia }\end{array}$ & $\begin{array}{l}\text { bt-gnaisse } \\
\text { porfiroclástico }\end{array}$ & $\begin{array}{c}465.95 \\
7541.42\end{array}$ & SnR & $\begin{array}{c}\text { S } 80 / 86 \\
\text { L } 160 / 32\end{array}$ & 1,77 & 1,71 & 1,04 & $1.22: 1.18: 0.69$ & 0,05 & 9,79 & 0,88 & 0,7 & 0,54 & 0,45 & 10 & 12 \\
\hline R16att & $\begin{array}{l}\text { Complexo } \\
\text { Paraisópolis }\end{array}$ & gnaisse enderbítico & $\begin{array}{c}465.79 \\
7531.94 \\
\end{array}$ & $\mathrm{Sn}+1$ & $\begin{array}{l}\text { S } 332 / 69 \\
\text { L } 62 / 10\end{array}$ & 1,74 & 1,56 & 1,12 & $1.25: 1.12: 0.72$ & 0,21 & 3,72 & 0,61 & 0,6 & 0,46 & 0,41 & 3 & 5 \\
\hline R585btt & $\begin{array}{l}\text { Complexo } \\
\text { Paraisópolis }\end{array}$ & gnaisse granulítico & $\begin{array}{c}463.71 \\
7530.16 \\
\end{array}$ & SnR & \begin{tabular}{l|} 
S 80/52 \\
L 65/48 \\
\end{tabular} & 1,57 & 1,52 & 1,03 & $1.17: 1.14: 0.75$ & 0,06 & 5,22 & 0,86 & 0,5 & 0,42 & 0,36 & 14 & 20 \\
\hline $\mathrm{F} 13 \mathrm{tt}$ & $\begin{array}{c}\text { Grupo } \\
\text { Andrelândia } \\
\end{array}$ & $\begin{array}{c}\text { bt-gnaisse } \\
\text { milonitizado }\end{array}$ & $\begin{array}{c}462.33 \\
7532.44 \\
\end{array}$ & $\mathrm{Sn}+1$ & \begin{tabular}{ll|} 
S & $110 / 60$ \\
L & $194 / 10$ \\
\end{tabular} & 2,12 & 1,87 & 1,13 & $1.34: 1.18: 0.63$ & 1,15 & 14,45 & 0,67 & 0,9 & 0,64 & 0,57 & 12 & 10 \\
\hline $\mathrm{R} 42 \mathrm{tt}$ & $\begin{array}{c}\text { Grupo } \\
\text { Andrelândia } \\
\end{array}$ & $\begin{array}{c}\text { bt-gnaisse } \\
\text { porfiroclástico }\end{array}$ & $\begin{array}{c}475.83 \\
7532.23 \\
\end{array}$ & SnR & $\begin{array}{c}\text { S } 50 / 48 \\
\text { L } 130 / 12 \\
\end{array}$ & 1,88 & 1,82 & 1,03 & $1.25: 1.21: 0.66$ & 0,04 & 17,19 & 0,90 & 0,8 & 0,60 & 0,50 & 11 & 9 \\
\hline F581tt & $\begin{array}{l}\text { Complexo } \\
\text { Paraisópolis }\end{array}$ & $\begin{array}{l}\text { gn granulitico } \\
\text { milonitizado }\end{array}$ & $\begin{array}{c}455.93 \\
7527.19\end{array}$ & Sn & $\begin{array}{l}\text { S } 154 / 28 \\
\text { L } 220 / 10\end{array}$ & 2,19 & 1,79 & 1,22 & $1.39: 1.14: 0.63$ & 0,28 & 6,36 & 0,49 & 0,8 & 0,62 & 0,58 & 10 & 9 \\
\hline F582t & $\begin{array}{l}\text { Complexo } \\
\text { Paraisópolis }\end{array}$ & bt-gnaisse bandado & $\begin{array}{c}459.32 \\
7526.28 \\
\end{array}$ & Sn & $\begin{array}{l}\text { S } 166 / 30 \\
\text { L } 236 / 5\end{array}$ & 2,17 & 2,11 & 1,03 & $1.31: 1.27: 0.60$ & 0,03 & $-34,26$ & 0,93 & 1,1 & 0,75 & 0,62 & 7 & 14 \\
\hline $\mathrm{F} 583 \mathrm{tt}$ & $\begin{array}{l}\text { Complexo } \\
\text { Paraisópolis }\end{array}$ & $\begin{array}{c}\text { Gnaisse } \\
\text { porfiroclástico } \\
\text { milonitizado }\end{array}$ & $\begin{array}{c}460.93 \\
7527.06\end{array}$ & $\mathrm{SnR}$ & $\begin{array}{l}\text { S } 195 / 80 \\
\text { L } 240 / 60\end{array}$ & 3,48 & 2,11 & 1,65 & $1.79: 1.09: 0.51$ & 0,58 & $-4,14$ & 0,20 & 1,3 & 0,90 & 0,89 & 8 & 8 \\
\hline F5t & $\begin{array}{c}\text { Complexo } \\
\text { Paraisópolis } \\
\end{array}$ & $\begin{array}{c}\text { bt-gnaisse } \\
\text { milonitizado }\end{array}$ & $\begin{array}{c}460.46 \\
7525.13 \\
\end{array}$ & $\mathrm{Sn}+1$ & $\begin{array}{l}\text { S } 162 / 52 \\
\text { L 248/15 }\end{array}$ & 2,61 & 1,81 & 1,44 & $1.56: 1.08: 0.60$ & 0,55 & 3,87 & 0,24 & 0,9 & 0,70 & 0,68 & 3 & 10 \\
\hline F74tt & $\begin{array}{l}\text { Complexo } \\
\text { Piracaia }\end{array}$ & $\begin{array}{c}\text { bt-gnaisse } \\
\text { milonitizado }\end{array}$ & $\begin{array}{c}465.26 \\
7515.89\end{array}$ & $\mathrm{Sn}+1$ & $\begin{array}{l}\text { S } 318 / 70 \\
\text { L } 233 / 10\end{array}$ & 2,95 & 2,62 & 1,13 & $1.49: 1.33: 0.51$ & 0,08 & $-4,29$ & 0,78 & 1,6 & 0,97 & 0,84 & 4 & 11 \\
\hline F136att & $\begin{array}{l}\text { Complexo } \\
\text { Piracaia }\end{array}$ & $\begin{array}{c}\text { bt-gnaisse } \\
\text { porfiroclástico } \\
\text { bandado }\end{array}$ & $\begin{array}{c}463.72 \\
7514.75\end{array}$ & $\mathrm{Sn}+1$ & $\begin{array}{l}\text { S } 132 / 67 \\
\text { L } 210 / 28\end{array}$ & 2,32 & 1,42 & 1,64 & $1.56: 0.95: 0.67$ & 1,51 & 0,53 & $-0,17$ & 0,8 & 0,60 & 0,60 & 10 & 13 \\
\hline $\mathrm{F} 122 \mathrm{tt}$ & $\begin{array}{l}\text { Complexo } \\
\text { Piracaia }\end{array}$ & $\begin{array}{c}\text { bt-gnaisse } \\
\text { protomilonitico }\end{array}$ & $\begin{array}{c}461.61 \\
7510.56 \\
\end{array}$ & $\mathrm{Sn}+1$ & $\begin{array}{l}\text { S } 142 / 90 \\
\text { L } 52 / 15\end{array}$ & 3,85 & 3,73 & 1,03 & I. $.58: 1.53: 0.41$ & 0,01 & $-3,43$ & 0,95 & 2,7 & 1,32 & 1,09 & 11 & 4 \\
\hline F188tt & $\begin{array}{l}\text { Complexo } \\
\text { Piracaia }\end{array}$ & anf-bt-gnaisse & $\begin{array}{c}476.61 \\
7516.55\end{array}$ & $\operatorname{SnR}$ & $\begin{array}{l}\text { S 288/65 } \\
\text { L 348/50 }\end{array}$ & 3,87 & 1,70 & 2,17 & $2.03: 0.91: 0.53$ & 1,82 & $-0,68$ & $-0,22$ & 1,5 & 0,98 & 0,96 & 2 & 7 \\
\hline $\mathrm{F} 127 \mathrm{tt}$ & Rocha İgnea & $\begin{array}{l}\text { bt-granito } \\
\text { porfiritico }\end{array}$ & $\begin{array}{c}451.59 \\
7545.66 \\
\end{array}$ & Sn & $\begin{array}{l}\text { S 226/10 } \\
\text { L 266/08 }\end{array}$ & 2,82 & 1,95 & 1,45 & $1.60: 1.10: 0.57$ & 0,47 & 15,73 & 0,29 & 1,0 & 0,76 & 0,74 & 16 & 9 \\
\hline F129t & $\begin{array}{c}\text { Grupo } \\
\text { Andrelândia } \\
\end{array}$ & $\mathrm{gr}-\mathrm{bt}$ gnaisse & $\begin{array}{c}451.16 \\
7543.70 \\
\end{array}$ & $\mathrm{Sn}+1$ & $\begin{array}{l}\text { S } 150 / 65 \\
\text { L 238/10 }\end{array}$ & 2,86 & 2,35 & 1,22 & $1.52: 1,25: 0.53$ & 0,16 & $-5,09$ & 0,63 & 1,4 & 0,88 & 0,81 & 4 & 11 \\
\hline $\mathrm{R} 125 \mathrm{tt}$ & $\begin{array}{c}\text { Grupo } \\
\text { Andrelândia }\end{array}$ & $\begin{array}{c}\text { anf-gn } \\
\text { granoblástico }\end{array}$ & $\begin{array}{c}451.56 \\
7541.20 \\
\end{array}$ & $\mathrm{Sn}+1$ & $\begin{array}{l}\text { S 130/70 } \\
\text { L 220/15 }\end{array}$ & 1,68 & 1,55 & 1,08 & $1.22: 1.13: 0.73$ & 0,15 & 4,14 & 0,69 & 0,6 & 0,45 & 0,39 & 17 & 21 \\
\hline F148tt & $\begin{array}{c}\text { Complexo } \\
\text { Amparo }\end{array}$ & bt-gnaisse bandado & $\begin{array}{c}485.75 \\
7553.93 \\
\end{array}$ & SnR & $\begin{array}{l}\text { S } 118 / 18 \\
\text { L } 42 / 08\end{array}$ & 1,92 & 1,37 & 1,40 & $1.39: 0.99: 0.72$ & 1,09 & 0,92 & $-0,03$ & 0,5 & 0,46 & 0,46 & 6 & 11 \\
\hline F205tt & $\begin{array}{c}\text { Grupo } \\
\text { Andrelândia }\end{array}$ & bt-gnaisse & $\begin{array}{c}443.04 \\
7534.49 \\
\end{array}$ & Sn & $\begin{array}{l}\text { S } 182 / 20 \\
\text { L } 256 / 08\end{array}$ & 2,06 & 1,73 & 1,19 & $1.35: 1.13: 0.65$ & 0,26 & 5,26 & 0,52 & 0,8 & 0,58 & 0,53 & 15 & 20 \\
\hline R100btt & $\begin{array}{c}\text { Complexo } \\
\text { Paraisópolis }\end{array}$ & gr-bt-gnaisse & $\begin{array}{c}444.98 \\
7522.66 \\
\end{array}$ & Sn & $\begin{array}{l}\text { S } 146 / 55 \\
\text { L } 172 / 33\end{array}$ & 1,72 & 1,69 & 1,02 & $1.21: 1.18: 0.70$ & 0,03 & 10,83 & 0,93 & 0,7 & 0,53 & 0,44 & 28 & 12 \\
\hline F98att & $\begin{array}{l}\text { Complexo } \\
\text { Paraisópolis }\end{array}$ & $\begin{array}{c}\text { Hornb-gn } \\
\text { milonitizado }\end{array}$ & $\begin{array}{c}445.91 \\
7520.69 \\
\end{array}$ & $\mathrm{Sn}$ & $\begin{array}{l}\text { S 204/40 } \\
\text { L 200/39 }\end{array}$ & 2,44 & 1,56 & 1,56 & $1.56: 1.00: 0.64$ & 1,01 & 0,99 & 0,00 & 0,8 & 0,63 & 0,63 & 20 & 17 \\
\hline F98btt & $\begin{array}{l}\text { Complexo } \\
\text { Paraisópolis }\end{array}$ & $\begin{array}{l}\text { gnaisse } \\
\text { milonitizado }\end{array}$ & $\begin{array}{c}445.91 \\
7520.69\end{array}$ & Sn & $\begin{array}{l}\text { S 204/40 } \\
\text { L 200/39 }\end{array}$ & 3,88 & 2,55 & 1,52 & $1.81: 1.19: 0.47$ & 0,34 & $-1,48$ & 0,38 & 1,6 & 1,03 & 0,98 & 5 & 4 \\
\hline $\mathrm{R} 23 \mathrm{Itt}$ & $\begin{array}{l}\text { Complexo } \\
\text { Paraisópolis }\end{array}$ & $\begin{array}{c}\text { bt-gnaisse } \\
\text { porfiroclástico }\end{array}$ & $\begin{array}{c}449.98 \\
7520.63 \\
\end{array}$ & Sn & $\begin{array}{l}\text { S 230/05 } \\
\text { L 260/00 }\end{array}$ & 1,84 & 1,61 & 1,14 & $1.28: 1.12: 0.70$ & 0,23 & 3,93 & 0,56 & 0,6 & 0.49 & 0,45 & 22 & 31 \\
\hline R68tt & $\begin{array}{l}\text { Complexo } \\
\text { Paraisópolis }\end{array}$ & gr-bt-gnaisse & $\begin{array}{c}451.20 \\
7520.01 \\
\end{array}$ & Sn & $\begin{array}{l}\text { S } 200 / 50 \\
\text { L } 230 / 42\end{array}$ & 1,82 & 1,79 & 1,02 & $1.23: 1.21: 0.67$ & 0,02 & 17,29 & 0,94 & 0,8 & 0,58 & 0,48 & 3 & 9 \\
\hline
\end{tabular}

Obs: (1) Rxy = Rxz/Ryz; (R) - resultados do método Rf/ $\phi$; (F) - resultados do método de Fry; (tt) - total de cristais; (S) - foliação; (L) -

lineação; $(\mathrm{Sn})$ - estrutura de baixo mergulho; $(\mathrm{Sn}+1)$ - estrutura transcorrente; $(\mathrm{SnR})$ - estrutura de baixo mergulho rotacionada.

amostras representativas das estruturas tangenciais $(\mathrm{Sn})$ o valor de $\theta^{\prime}$ é de $14^{\circ}$ nos dois planos cinemáticos, de $8^{\circ}$ e $11^{\circ}$ nas tangenciais rotacionadas e $7^{\circ}$ e $9^{\circ}$ nas transcorrentes $(S n+1)$, respectivamente nos planos XZ e YZ, o que indica a existência de componentes de cisalhamento simples nos dois planos cinemáticos.

$\mathrm{O}$ número de vorticidade $\left(\mathrm{W}_{\mathrm{K}}\right)$ expressa a medida da coaxilidade da deformação progressiva. Na representação gráfica de $\mathrm{W}_{\mathrm{K}}$ (Diagrama $\theta^{\prime} \times$ Rs - Figs. 8a,b) valores inferiores a 0.75 indicam o predomínio da componente de cisalhamento puro, enquanto para variações entre $0.75-1$ a deformação foi mais acomodada pelo cisalhamento simples (Fossen et al. 1994, Tikoff \& Fossen 1995).

A análise de $\mathrm{W}_{\mathrm{K}}$ para o total de cristais, nos planos $\mathrm{XZ}$ e $\mathrm{YZ}$, apresentou na maioria das amostras resultados abaixo da curva de $\mathrm{W}_{\mathrm{K}}=0.75$, o que indica o predomínio da componente de cisalhamento puro nos dois planos, independe da amostra provir de domínio de estruturas de baixo ângulo de mergulho, feições rotacionadas ou estututras transcorrente. Excetua-se deste conjunto as amostras 231 (YZ), 100b (XZ) e 98a (XZ), coletadas nas proximidades da ZC de Lourenço Velho, onde os valores entre as curvas de 0.75 e 0.9 (Fig. 8c) indicaram o predomínio de cisalhamento simples sobre o puro. É nesta parte da área que se concentram os indicadores cinemáticos de movimento de topo para NE, confirmando tratar-se de uma importante zona de transporte de massas desenvolvida ao longo da Zona de Sutura de Alterosa. 
$45^{\circ} 33^{\prime} 49^{\prime \prime}$
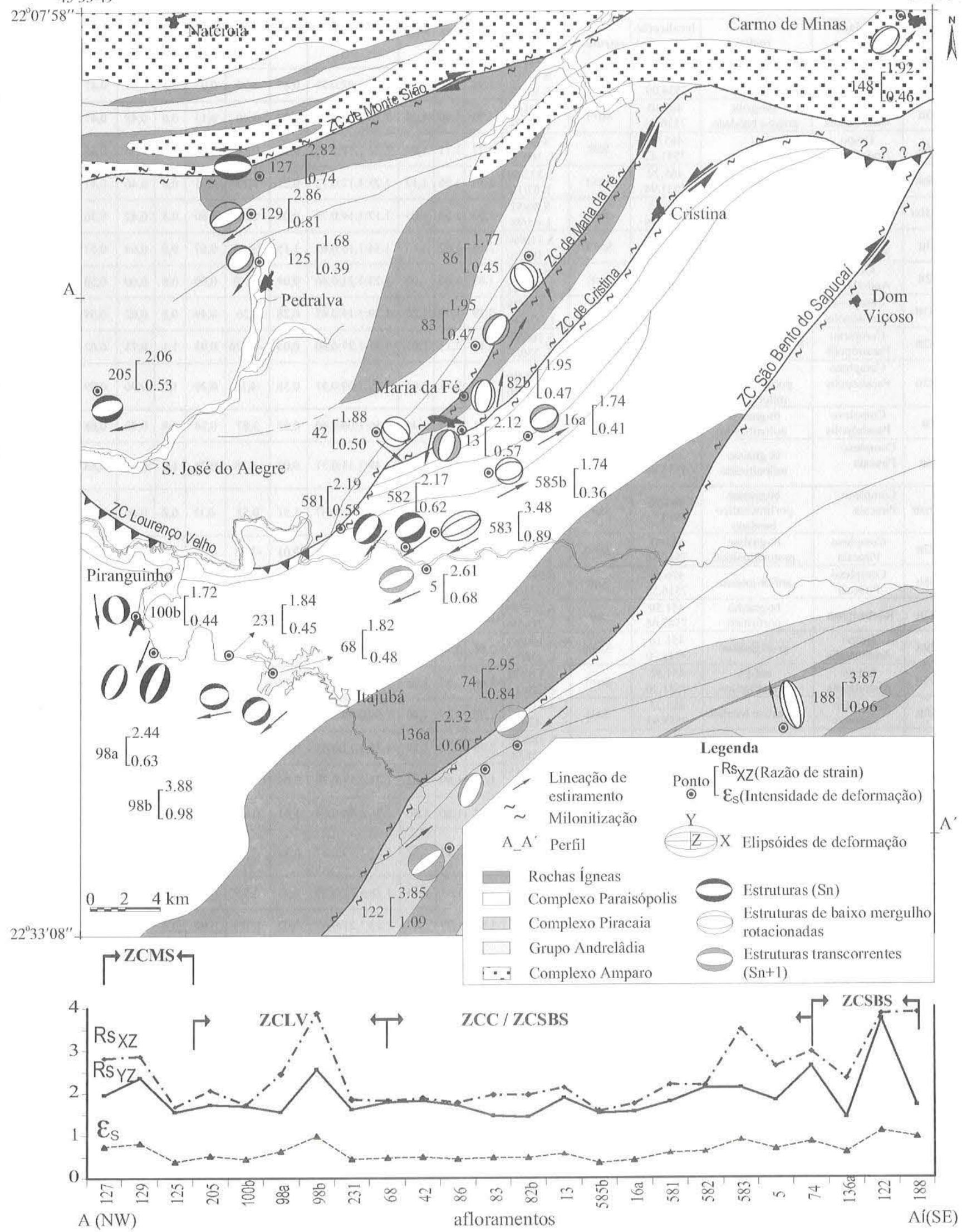

Figura 5 - Localização e orientação dos elipsóides de deformação em relação às principais estruturas da área. Parte inferior gráfico: variação de Rs nos planos XZ,YZ e da intensidade de deformação (es) das amostras analisadas. 


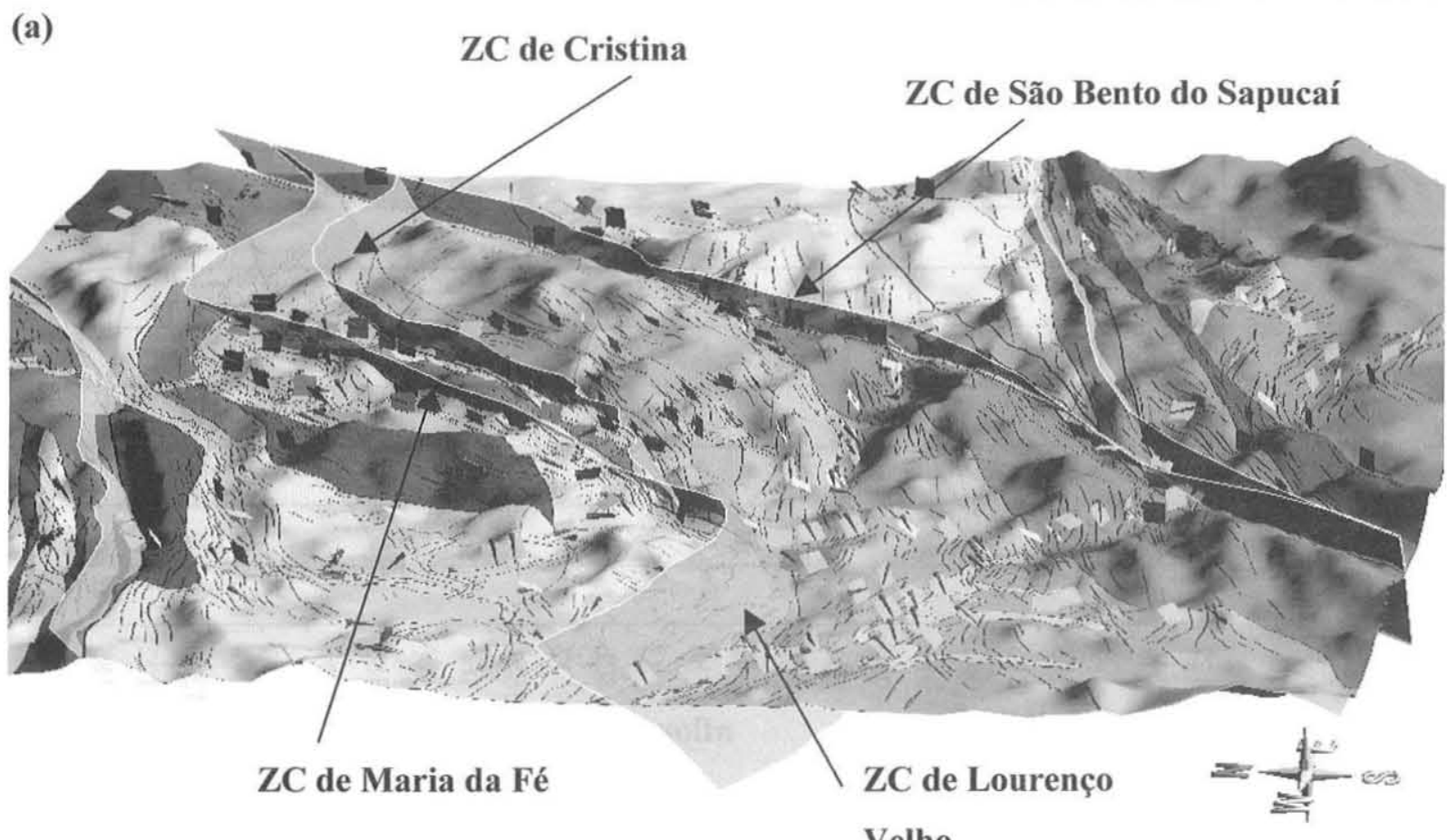

(b)

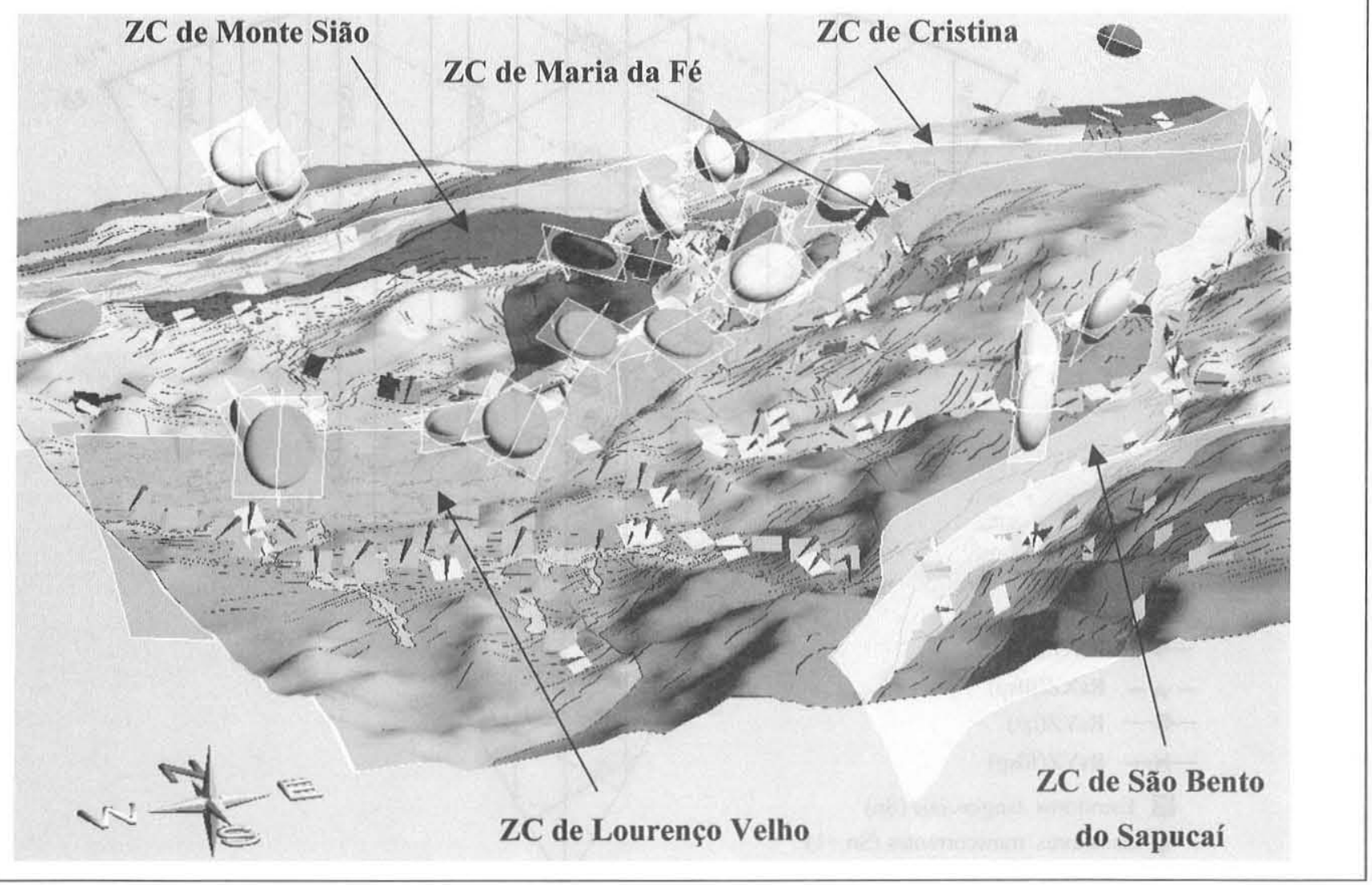

Figura 6 - Modelos topográficos sombreados da área estudada com sobreposição do mapa geológico (significado das cores na figura 5) e principais elementos estruturais. a) Visada para leste da Zona de Cisalhamento de Lourenço Velho (ZCLV). que constitui estrutura de baixo ângulo com foliações para SW, e lineações caindo para o mesmo quadrante. Na porção central da figura a ZCLV conecta-se às ZCs de Cristina e Maria da Fé, de direção NE-SWE. b) Visada para norte, com representação dos elipsóides de deformação associados às zonas de cisalhamento de Monte Sião, Maria da Fé, de Cristina, Lourenço Velho e de São Bento do Sapucai. As cores das zonas de cisalhamento e das foliações (plaquetas) indicam o evento correspondente: verde (estruturas de baixo ângulo associadas a Dn); amarelo (transcorrentes $\mathrm{Dn}+1$ ) e vermelho (estruturas originalmente de baixo ângulo, rotacionadas). Setas vermelhas sobre a foliação representam as lineações de estiramento, que são frontais sobre as plaquetas verdes (Sn/Ln) e direcionais sobre as plaquetas amarelas $(\mathrm{Sn}+1 / \mathrm{Ln}+1)$. 
a)

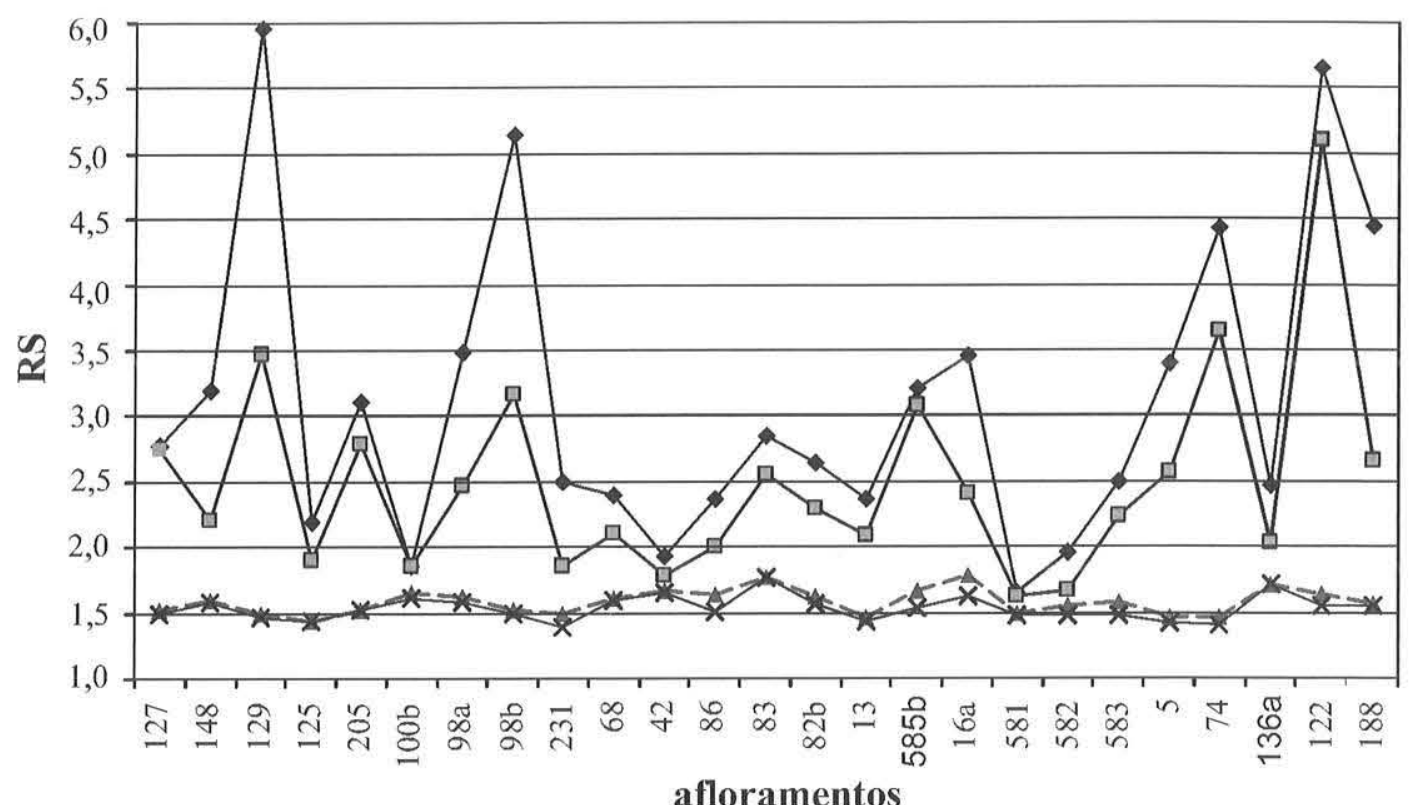

b)

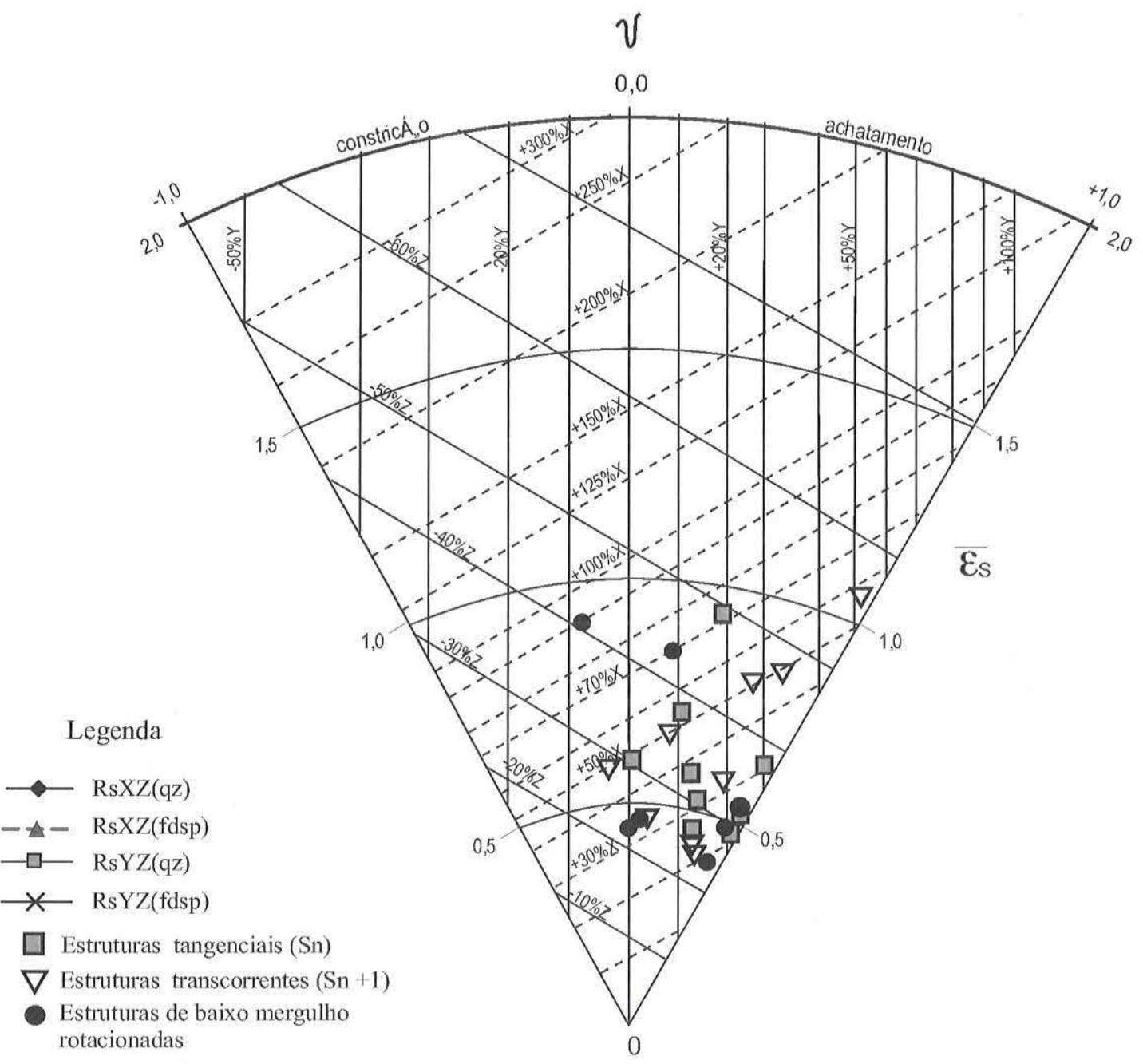

Figura 7 - (a) Variação da elipticidade (Rs) das amostras analisadas considerando-se marcadores de quartzo e feldspato nos planos XZ e YZ; (b) Posicionamento das amostras no Diagrama de Hsu.

A análise discriminante por mineral mostra valores de $\mathrm{W}_{\mathrm{k}}$ concentrados entre as curvas de 0 e 0.4 para o feldspato e entre 0 e 0.9 para o quartzo, nos planos XZ e em YZ, indicando que o quartzo também contribuiu mais intensamente para a acomodação da componente de cisalhamento simples nos processos colisionais. 

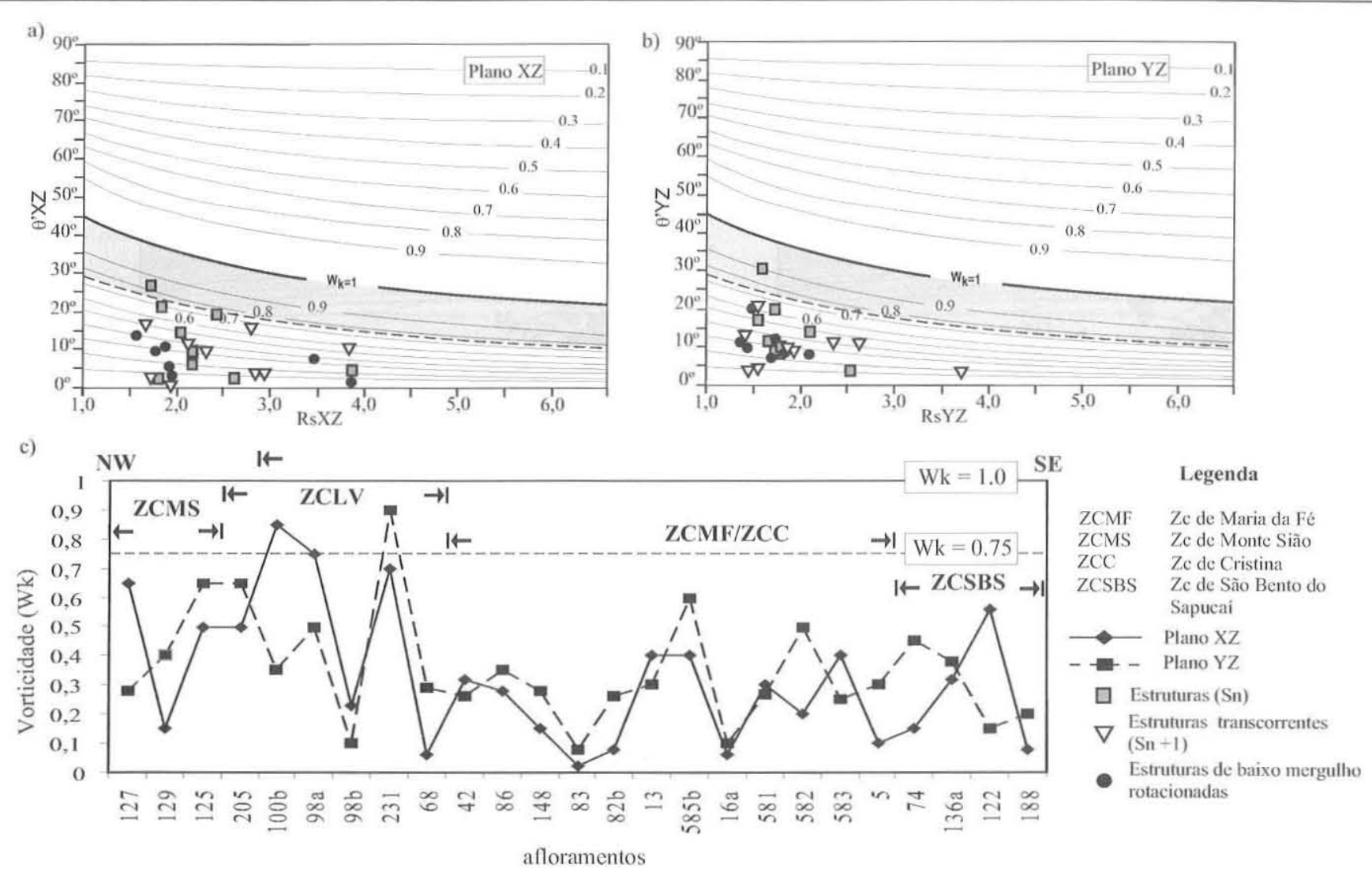

afloramentos

Figura 8 - (a,b) Diagramas de Rs x Teta' indicando predominio de cisalhamento puro nos planos XZ e YZ (amostras abaixo da linha pontilhada, onde $0.75<W k<1$ ); (c) Perfil Wk.

A intensidade de deformação cisalhante (gama) na maioria das amostras apresenta baixos valores de $\gamma$, entre 0.2 e 0.4 nos dois planos (Figs. 9a,b). Apenas algumas amostras pertencentes à Zona de Cisalhamento de Lourenço Velho, de maior movimento diferencial (deslocamento), mostram valores de $\gamma$ em torno de 0.5 (Fig. 9c). Na análise discriminada por tipo de marcador o feldspato forneceu os menores valores de $\gamma(<0.3)$, enquanto o quartzo os maiores valores $(0.3<\gamma<0.8)$ nos dois planos, demonstrando que o mesmo também acomodou preferencialmente a deformação cisalhante nas amostras estudadas.

CONCLUSÕES Na região de Cristina e Itajubá, Sul de Minas Gerais, o complexo arcabouço tectônico apresenta elementos planares e lineares dúcteis, que podem ser agrupados em três tipos de domínios estruturais distintos: i) estruturas (Dn) com baixo mergulho para SW, preservados nas proximidades da Zona de Cisalhamento de Lourenço Velho; ii) estruturas de baixo ângulo de mergulho que sofreram rotação ao logo das zonas de cisalhamento sinistrais de Maria da Fé e Cristina, que configuram zonas de transferência; e iii) estruturas transcorrentes caracterizadas por foliação milonítica $(\mathrm{Sn}+1)$, desenvolvidas ao longo de zonas de cisalhamento dextrais (ZCs de São Bento do Sapucaí e Monte Sião).

Estes elementos estruturais registram dois eventos tectônicos principais: a) Dn, formador da foliação regional $\mathrm{Sn}$ de direção NW-SE e baixo mergulho para SW, com paragêneses de fácies granulito a anfibolito e relacionado à Orogênese Brasília ocorrida entre a 630 e $610 \mathrm{Ma}$. A rotação sinistral progressiva de Sn para a direção aproximada W-E, com mergulho para Sul, até a atitude NE-SW, ao longo das ZCs de Maria da Fé e Cristina, que configuram zonas de transferência, é atribuída ao mesmo regime tectônico compressivo WSW-ENE; e b) Dn+1, marcado pela foliação milonítica $(\mathrm{Sn}+1)$ de fácies anfibolito baixo ao longo das ZCs transcorrentes dextrais de São Bento do Sapucaí (NE-SW) e de Monte Sião (ENE-WSW), integrantes do CTRPS e vinculados aos processos colisionais oblíquos do Cinturão Ribeira (590-540 Ma), cuja zona de sutura (Abre Campo) encontra-se a sudeste da área. Estruturas extensionais dúcteis sobre a foliação $\mathrm{Sn}$, com sentido para SW, já reportadas por Hackspacher et al. (1991) e Campos Neto et al. (2004), não puderam no presente trabalho ser seguramente atríbuídas a um ou a outro evento principal, necessitando de investigações adicionais específicas, inclusive com datações de Ar-Ar. As estruturas descritas são atribuídas a dois eventos tectônicos principais: Dn relacionado à orogênese Brasília (Sistema Orogênico Tocantins), durante a qual foram alçados os granulitos do Complexo Paraisópolis, representando a crosta inferior da placa superior (Bloco São Paulo), sobre os metassedimentos do Grupo Andrelândia e o Complexo Amparo/São Gonçalo do Sapucaí (placa inferior); b) Dn+1 responsável pela formação em fácies anfibolito baixo da foliação $(\mathrm{Sn}+1)$, relacionadas ao Cinturão Transpresivo Rio Paraíba do Sul e vinculadas aos processos orogenéticos do Cinturão Ribeira durante colisão oblíqua de direção E-W.

A análise de deformação nos planos $\mathrm{XZ}$ e YZ revelou predomínio de elipsóides deformação finita oblatos e de cisalhamento puro sobre o simples. O cisalhamento simples predomina apenas em amostras próximas a Zona de Cisalhamento de Lourenço Velho, que constitui uma importante zona de transporte de massas para NE, sendo esta estrutura interpretada como um segmento Zona de Sutura de Alterosa, deslocado pelo feixe de transcorrências dextrais do Cinturão Transpressivo Rio Paraíba do Sul.

A análise individual por tipo de marcador indica que o quart- 


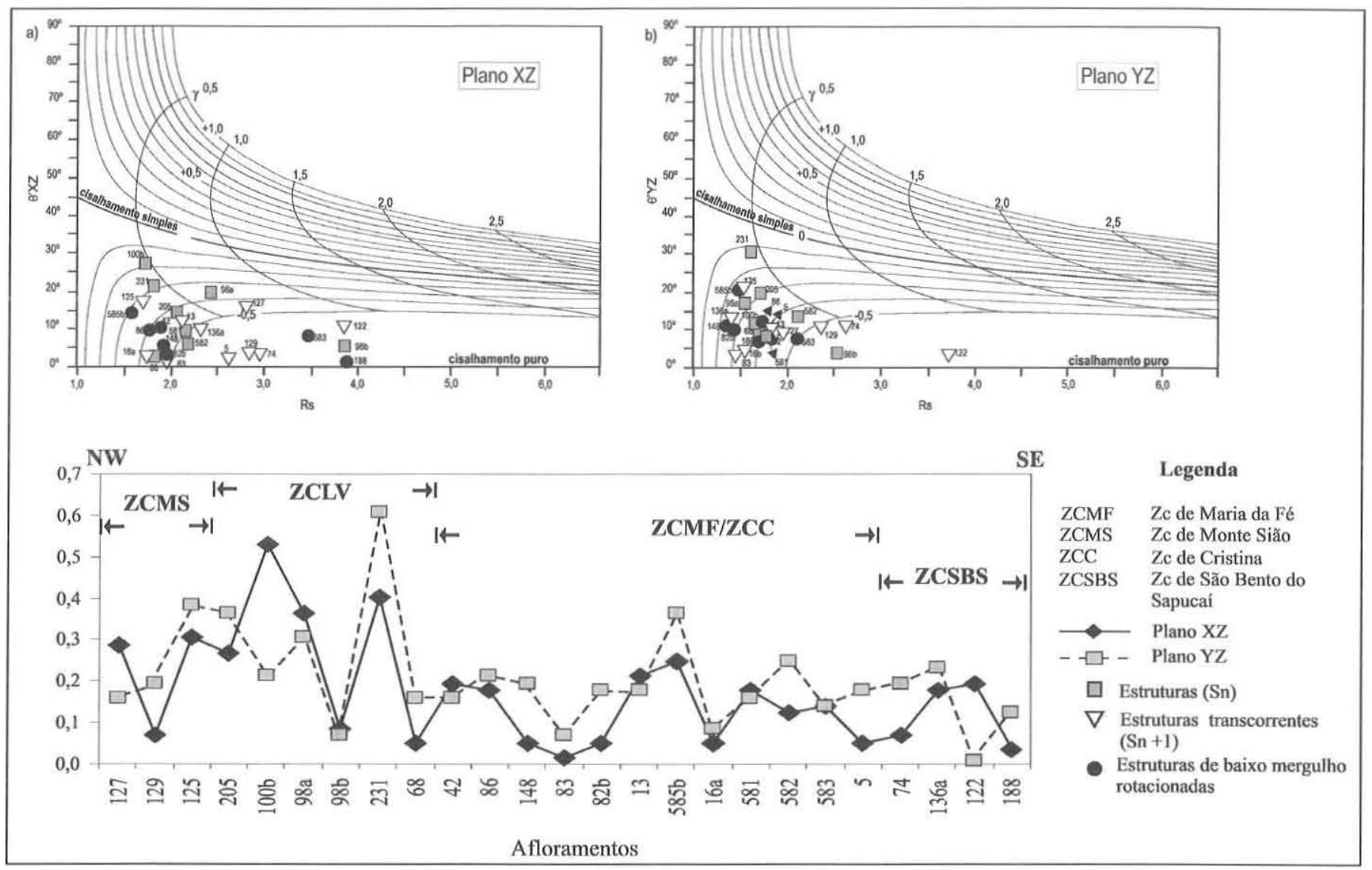

Figura 9 - Variação na orientação das elipses de deformação ( $q$ ') e elipticidade nos planos XZ (a) e YZ (b) para diferentes curvas de cisalhamento (g): (c) Perfil da intensidade de deformação cisalhante gama (g) ao longo de seção esquemática NW-SE.

zo exerceu fundamental importância reológica para o desenvolvimento de zonas de cisalhamento (alta deformação), acomodando, em relação ao feldspato, com maior intensidade as tensões regionais, tanto através de distorção interna (Rs) como de rotação dos marcadores.

O estudo da obliqüidade média $\theta^{\prime}$ mostrou a atuação de componentes de cisalhamento simples nos dois planos cinemáticos, sendo que em YZ ocorre maior assimetria entre o eixo maior da elipse de deformação em relação à foliação, o que demonstra a complexidade da deformação tridimensional.

$\mathrm{O}$ estudo do número de vorticidade $\left(\mathrm{W}_{\mathrm{K}}\right)$ indica predomínio da componente de cisalhamento puro sobre o simples, tanto nas amostras provindas de domínios tectônicos tangenciais como transcorrentes. Isto sugere que o peso das massas crustais colididas durante a duplicação crustal superou, pelo menos temporalmente, o cisalhamento relacionado ao transporte de massas, para a caracterização textural finita das rochas que acomodaram os processos orogênicos nesta região (Ebert \& Hasui 1998). O predomínio de cisalhamento simples sobre o puro foi identificado em amostras localizadas próximas à Zona de Cisalhamento de Lourenço Velho, indicando tratar-se de uma importante zona de transporte de massas.

A pequena diferença entre os resultados das amostras coletadas em domínios tangenciais e transcorrentes sugere que: a) a maior parte das últimas corresponde às estruturas mais antigas (Dn) que foram rotacionadas; b) não sofreram forte deformação incremental devido às zonas de cisalhamento transcorrentes, e c) que as zonas de cisalhamento transcorrente têm caráter fortemente transpressivo, com predomínio de encurtamento ortogonal a elas.

Agradecimentos Os autores expressam agradecimentos aos relatores da RBG pelas sugestões no texto original, bem como ao CNPq por apoio financeiro ao projeto e concessão de bolsas. 


\section{Referências}

Almeida, S.H.S. \& Ebert H.D. 1998. Estruturação tectônica da borda Norte da Cunha de Guaxupé e da Sutura de Alterosa na Região de Alfenas, Sudoeste do Estado de Minas Gerais. Geociências, 17(2):421-443.

Braga 1.F. 2002. Análise de Deformação de Rochas Infracrustais da Região de Cristina e Itajubá - MG. Tese de Doutorado, Instituto de Geociências e Ciências Exatas, Universidade Estadual Paulista, $197 \mathrm{p}$.

Campanha G.A.C. \& Sadowski G.R. 2002. Determinações da deformação finita em metassedimentos da Faixa Ribeira na região de Iporanga e Apiaí, SP. Revista Brasileira de Geociências, 32 (1):107-118.

Campos Neto M.C. 2000. Orogenic system from Southwestern Gondwana: an approach to Brasiliano-Pan African Cycle and orogenic collage in Southeastern Brazil. In: U.G. Cordani, E.J. Milani, A. Thomaz Filho, D.A. Campos (eds.) Tectonic Evolution of South America. International Geological Congress, 31, p.335-365.

Campos Neto M.C., Basei M. A. S., Vlach S. R. F., Caby R., Szabó G.A.J., Vasconcelos P. 2004. Migração de orógenos e superposição de orogêneses: um esboço da Colagem Brasiliana no sul do Cráton do São Francisco, SE - Brasil. Geologia USP - Série Científica, $4(1): 13-40$.

Dayan H. \& Keller J.V.A. 1990. AZona de Cisalhamento do Rio Paraíba do Sul nas vizinhanças de Três Rios (RJ): uma análise da deformação dada por algumas feições estruturais. Revista Brasileira de Geociências, 19:494-506.

Ebert H.D. \& Hasui Y. 1998. Transpressional tectonics and strain partitioning during oblique collision between three plates in the Precambrian of southeast Brazil. In: R.E. Holdsworth, R.A. Strachan, J.F. Dewey. (eds.) Continental Transpressional/Transtensional Tectonics. Geological Society, London, Special Publications v. 135, p. 231-252.

Ebert H. D., Hasui Y., Sartonato G., Almeida S.H.S., Costa J.B.S. 1993. Arcabouço estrutural e tectônica transpressiva das faixas móveis da borda sul e sudeste do Cráton do São Francisco e da Sintaxe de Guaxupé. In: SBG, Simp. Nacional de Estudos Tectônicos, 4, Boletim, 12:254-258.

Erslev E. A. 1993. Strain Analysis program (Instrain 3.02). Departament of Earth Resources, Colorado.

Fiori A.P. - 1997 - Introdução à análise de deformação. Ed. UFPr. Curitiba, $249 \mathrm{p}$.

Fry N. 1979. Radom point distributions and strain measurement in rocks. Tectonophysics, Amsterdan, 60:89-105.

Fossen H., Tikoff B., Teyssier C. 1994. Strain modeling of transpressional and transtensional deformation. Norsk Geologisk Tidsskrifi, 74:134-145.
Hackspacher P.C., Oliveira M.A.F. de, Hasui Y., Ebert H.D. 1991. Bloco Granulítico de Cristina (MG), exemplo de alçamento crustal síncrono ao Sistema de Cisalhamento Monte Sião/Jundiuvira. In: SBG/SP, Simp. Nacional de Estudos Tectônicos, Rio Claro-SP, Atas, p. 5457.

Hackspacher P.C., Fetter A.H., Ebert H.D., Janasi V. de A., Dantas E.L., Oliveira M.A.F. de, Braga I.F., Negri F. de A. 2003. Magmatismo há 660-640 Ma no Domínio Socorro: Registros de convergência pré-colisional na aglutinação do Gondwana Ocidental. Revista do Instituto de Geociências USP, 3:85-96.

Heilbron M., Pedrosa-Soares A.C., Campos Neto M.C., Silva, L.C., Trouw R.A.J., Janasi V.A. 2004. Província Mantiqueira. In: V. Mantesso-Neto, A. Bartorelli, C.D.R. Carneiro, B.B. Brito Neves (Orgs.) Geologia do Continente Sul-Americano: Evolução e obra de Fernando Flávio Marques de Almeida. Beca, São Paulo, Cap.13, pp.: 203-234.

Haralyi N .L. E., Hasui Y., Mioto J.A., Hamza V.M., Rodrigues C.R. 1985. Ensaio sobre a estruturação crustal do Estado de Minas Gerais com base na informação geofísica. Boletim Especial da Sociedade Brasileira de Geologia, p. 71-93.

Holcombe R.J. 2000. Strain Calculator. Programa de computador - University of Queensland, Austrália. Disponivel em: http:7www.earthsciences.uq.edu.au/ rodh/software.

Hsu K.J. 1966. The characteristics of coaxial and non-coaxial strain paths. - J.Strain Anal., 1:216-222.

Lisle R.J. 1985. Geological strain analysis. Pergamon Press, 76 p.

Morais S.M. (Org.) 1999. Integração Geológica da Folha Guaratinguetá-SF.23-Y-C-Escala 1:250.000. São Paulo, CPRM, 28 p.

Morales N. 1993. Evolução tectônica do Cinturão de Cisalhamento Campo do Meio na sua porção ocidental. Tese de Doutoramento, Instituto de Geociências e Ciências Exatas, Universidade Estadual Paulista, $220 \mathrm{p}$.

Ramsay J.G., Huber M.I. 1983. The technics of modern structural geo$\log y$. Academic Press, London, 1307p.

Tikoff B. \& Fossen H. 1995. The limitations of three-dimensional vorticy analysis. Journal of Structural Geology, 17(12): 1771-1784.

Trouw R.A.J., Heilbron M., Ribeiro A., Paciullo F., Valeriano C.M., Almeida J.C.H., Tupinambá M., Andreis, R.R. 2000. The Central Segment of the Ribeira Belt. In: U.Cordani, A. Thomaz Filho, D.A. Campos Neto (eds.) Tectonic Evolution of South America. p. 287310.

Manuscrito A1585 Aprovado em 13 de setembro de 2006 